\title{
Detecting understory plant invasion in urban forests using LiDAR
}

\author{
Kunwar K. Singh ${ }^{\mathrm{a}, *}$, Amy J. Davis ${ }^{\mathrm{b}}$, Ross K. Meentemeyer ${ }^{\mathrm{a}}$ \\ a Center for Geospatial Analytics, Department of Forestry and Environmental Resources, North Carolina State University, Raleigh, NC 27695, USA \\ ${ }^{\mathrm{b}}$ Department of Geography and Earth Sciences, University of North Carolina, Charlotte, NC 28223, USA
}

\section{A R T I C L E I N F O}

\section{Article history:}

Received 14 October 2014

Received in revised form 18 January 2015

Accepted 22 January 2015

Available online 12 February 2015

\section{Keywords:}

Biological invasion

Chinese privet

Data integration

IKONOS

LiDAR

Ligustrum sinense

Random forest

\begin{abstract}
A B S T R A C T
Light detection and ranging (LiDAR) data are increasingly used to measure structural characteristics of urban forests but are rarely used to detect the growing problem of exotic understory plant invaders. We explored the merits of using LiDAR-derived metrics alone and through integration with spectral data to detect the spatial distribution of the exotic understory plant Ligustrum sinense, a rapidly spreading invader in the urbanizing region of Charlotte, North Carolina, USA. We analyzed regional-scale $L$. sinense occurrence data collected over the course of three years with LiDAR-derived metrics of forest structure that were categorized into the following groups: overstory, understory, topography, and overall vegetation characteristics, and IKONOS spectral features - optical. Using random forest (RF) and logistic regression (LR) classifiers, we assessed the relative contributions of LiDAR and IKONOS derived variables to the detection of $L$. sinense. We compared the top performing models developed for a smaller, nested experimental extent using RF and LR classifiers, and used the best overall model to produce a predictive map of the spatial distribution of $L$. sinense across our country-wide study extent. RF classification of LiDAR-derived topography metrics produced the highest mapping accuracy estimates, outperforming IKONOS data by $17.5 \%$ and the integration of LiDAR and IKONOS data by $5.3 \%$. The top performing model from the RF classifier produced the highest kappa of $64.8 \%$, improving on the parsimonious LR model kappa by $31.1 \%$ with a moderate gain of $6.2 \%$ over the county extent model. Our results demonstrate the superiority of LiDAR-derived metrics over spectral data and fusion of LiDAR and spectral data for accurately mapping the spatial distribution of the forest understory invader $L$. sinense.
\end{abstract}

(c) 2015 Elsevier B.V. All rights reserved.

\section{Introduction}

Biological invasions are one of the leading contributors to changes in regional and global biodiversity (Asner and Vitousek 2005; Simberloff et al., 2013). The rapid spread of invaders across a range of ecosystems makes it challenging to accurately assess the spatial distribution and abundance in a timely and cost-effective manner at a desired spatio-temporal scale (Huang and Asner, 2009). Remote sensing has facilitated advances in mapping and monitoring biological invasions across a range of ecosystems, including deciduous forests (Resasco et al., 2007), wetlands (Laba et al., 2008), rangelands (Glenn et al., 2005), coastal environments (Hestir et al., 2008), and tropical forests (Asner et al., 2008). These successes are primarily attributable to sensor

\footnotetext{
* Corresponding author at: Department of Forestry and Environmental Resources, North Carolina State University, Raleigh, NC 27695, USA. Tel.: +1 704359 7139; fax: +1 9195153439 .

E-mail addresses: kun2001@gmail.com (K.K. Singh), amyjsdavis@gmail.com (A.J. Davis), rkmeente@ncsu.edu (R.K. Meentemeyer).
}

characteristics, recent advancements in mapping algorithms, and synergistic use of datasets from multiple instruments. While some success has been achieved with high-to-moderate resolution imagery, hyperspectral imagery has demonstrated the most promising results (Huang and Asner, 2009). The growing number of invasions in forests pushes the limits of remote sensing performance, particularly in detecting exotic plant invasions in the understory where regeneration and recruitment are most impacted by invaders (Becker et al., 2013). Canopy cover closure, canopy gap shadowing, mortality of native plant species, and terrain variability in the understory of forest ecosystems limit accurate detection of understory invaders (Asner et al., 2008). Successful detection often depends upon open views of the species of interest (Resasco et al., 2007) and the timing of remote sensing imagery to take advantage of phenological patterns in the overstory, i.e., after leaf abscission (Becker et al., 2013; Tuanmu et al., 2010). To date, detection of understory plant invasions is largely reliant on field surveys, but cost and data collection times limit the number of locations that can be assessed. Although spatially explicit models such as species distribution models (SDMs) have been used to predict the probability of invader presence in non-sampled 
locations, there has been little success to date in applying these models to new regions outside the study extent. Successful management of broad-scale exotic invaders in the understory of forest ecosystems requires new techniques using minimal field data for mapping their spatial distribution and abundance.

Several studies have examined the potential of using fieldmeasured SDMs augmented with optical remote sensing to detect understory plant invaders (Estes et al., 2010; Rushton et al., 2004). Andrew and Ustin (2009) suggest that the mapping of the distribution of invasives and sites prone to invasion using remote sensing can be improved by including covariates characterizing the environmental suitability of the site for the invader, such as slope, solar radiation index, and soil moisture index. Other studies have examined the efficacy of moderate-to-high resolution and multi-to-hyperspectral remote sensing data to detect understory invaders based on variability in seasonal and environmental responses (Wilfong et al., 2009). For example, spectral differences in the seasonal phenology of understory vegetation and deciduous tree canopy during leaf-off conditions can be used to detect understory vegetation, but success is limited to narrow windows of senescence time (Chastain and Townsend, 2007). The spatial and vertical heterogeneities of forest vegetation limit the utility of spectral-based approaches for detecting the structure and composition of understory vegetation even where distinguishing physiological and phenotypic characteristics of an invader exist (Homolova et al., 2013). Studies have also attempted to improve the detection of understory vegetation by using sub-pixel multivariate algorithms, such as artificial neural networks, linear mixture models, and maximum entropy (Linderman et al., 2004; Tuanmu et al., 2010; Wang et al., 2009). While some studies have shown potential for using spectral remote sensing to detect understory invasives by coupling the phenological patterns and improved algorithms, questions remain regarding the efficient use of structural remote sensing.

Light detection and ranging (LiDAR) offers the possibility of accurately detecting understory invasive shrubs on the basis of their structural characteristics as distinguished from canopy species since it provides three dimensional data on the structure and arrangement of vegetation across all forest strata (Falkowski et al., 2009; Goetz et al., 2010). LiDAR data have been widely used for quantifying structural characteristics (e.g., tree diameter, height, density, and biomass) of forest stands (Hudak et al., 2008; Jaskierniak et al., 2011), mapping snags and understory shrubs (Martinuzzi et al., 2009), characterizing successional stages of forest stands (Falkowski et al., 2009), estimating native understory vegetation cover (Estornell et al., 2011; Wing et al., 2012), and identifying tree species. To complement LiDAR's narrow spectral range, structural covariates of LiDAR have been combined with multito-hyperspectral remote sensing imagery to map forest structural attributes, plant species distribution, forest biomass, and forest canopy fuels (Mutlu et al., 2008; Popescu et al., 2004). To date, LiDAR technologies 'alone' or through 'fusion' with spectral data have not been leveraged to improve our ability to detect understory plant invaders in urban forest ecosystems at regional scales. In addition, detection information is typically limited to direct LiDAR measurement (e.g., shrub height) of the plant individuals themselves while ignoring other forest and landscape characteristics (e.g., topographic position) that may affect the distribution and growth of invaders.

In this study, we examine the utility of multi-return LiDAR data, IKONOS imagery, and the combination of data from both sensors for detecting and mapping understory invaders. Using Ligustrum sinense (commonly known as Chinese privet) as a case study, we focus on the urban to rural forests located in Mecklenburg County, North Carolina to analyze the performance of LiDAR data, IKONOS, and the data combination. We incorporate additional forest and landscape characteristics to detect this plant invader by analyzing combinations of datasets developed from categorized LiDAR-derived variables (overstory, understory, topography, and overall vegetation characteristics) and IKONOS spectral features (optical) using random forest (RF) and logistic regression (LR) classifiers. We then compare the top performing models and apply the best model to map the probability of $L$. sinense occurrence across the heterogeneous study region.

\section{Methods}

\section{Study system}

The naturalized $L$. sinense has invaded over one million hectares of forests across a large portion of the southeastern United States, and the species is listed among the top invasives in many states (Miller et al., 2008). It grows in a wide variety of habitats and environmental conditions, including abandoned farmlands and disturbed areas, where it forms impenetrable thickets with a typical height range of 1-5 m, occasionally reaching heights of $10 \mathrm{~m}$ (Fig. 1). It is a prolific seed producer with a high germination rate. Its ability to tolerate both flooding and shade makes it well suited to the floodplains and riparian zones of forests (Brown and Pezeshki, 2000). The abundance of $L$. sinense threatens forest ecosystems by altering the diversity, composition, and structure of forests (Greene and Blossey, 2012). The growing threat of large-scale ecosystem modification by $L$. sinense is of extreme concern for land managers and conservationists in the United States (Hanula et al., 2009).

A growing number of studies have examined $L$. sinense invasion and impacts on ecosystem services across much of the southeastern United States. The invasive has threatened to displace endangered Miccosukee gooseberry (Ribes echinellum) in Florida (Langeland and Burks, 1998). Invasions by $L$. sinense have been linked to several negative outcomes including reduced herbaceous species in understory and suppressed tree regeneration in a mixed hardwood forest in western North Carolina (Merriam and Feil, 2002); decreased beetle diversity in northeastern forests of Georgia (Ulyshen et al., 2010); and declining populations of the Schweintz's sunflower (Helianthus schweinitzii) found in the central Piedmont region of North and South Carolina (USFWS, 1991). Faulkner et al. (1989) found that dense thickets of $L$. sinense in forested areas of Tennessee produce large quantities of litter and act like 'umbrellas' preventing the infiltration of leaf litter from the native tree canopy. L. sinense ranked fourth among the top invasive plants in North Carolina with high prevalence in urban areas (EDDMapS, 2014).

The highly fragmented and urbanizing forested landscape of Mecklenburg County $\left(1415 \mathrm{~km}^{2}\right)$, located in the CMR of North Carolina within the Piedmont province of the southeastern United States (Fig. 2a), provides an ideal system for this case study. The study system is characterized by rolling topography with a forest-farmland mosaic that comprises a mix of secondary growth oak-hickory-pine forests and stands of loblolly pine, which dominate clear-cuts and abandoned farmland Singh et al. (2015).

\section{Field data collection}

We established a network of 346 randomly distributed field plots within 75 forested sites in the study system (Fig. 2b). We collected data at 139 field plots during the leaf-on season of 2009 and 2010 from mid-May to the end of July, and at 207 field plots during the leaf-off season of 2012 from mid-January to mid-March. Impassability to field plots due to thick understory vegetation in the leaf-on season forced us to collect data in the leaf-off season at the peak of senescence and abscission. We used a stratifiedrandom strategy to ensure adequate representation of upland and 

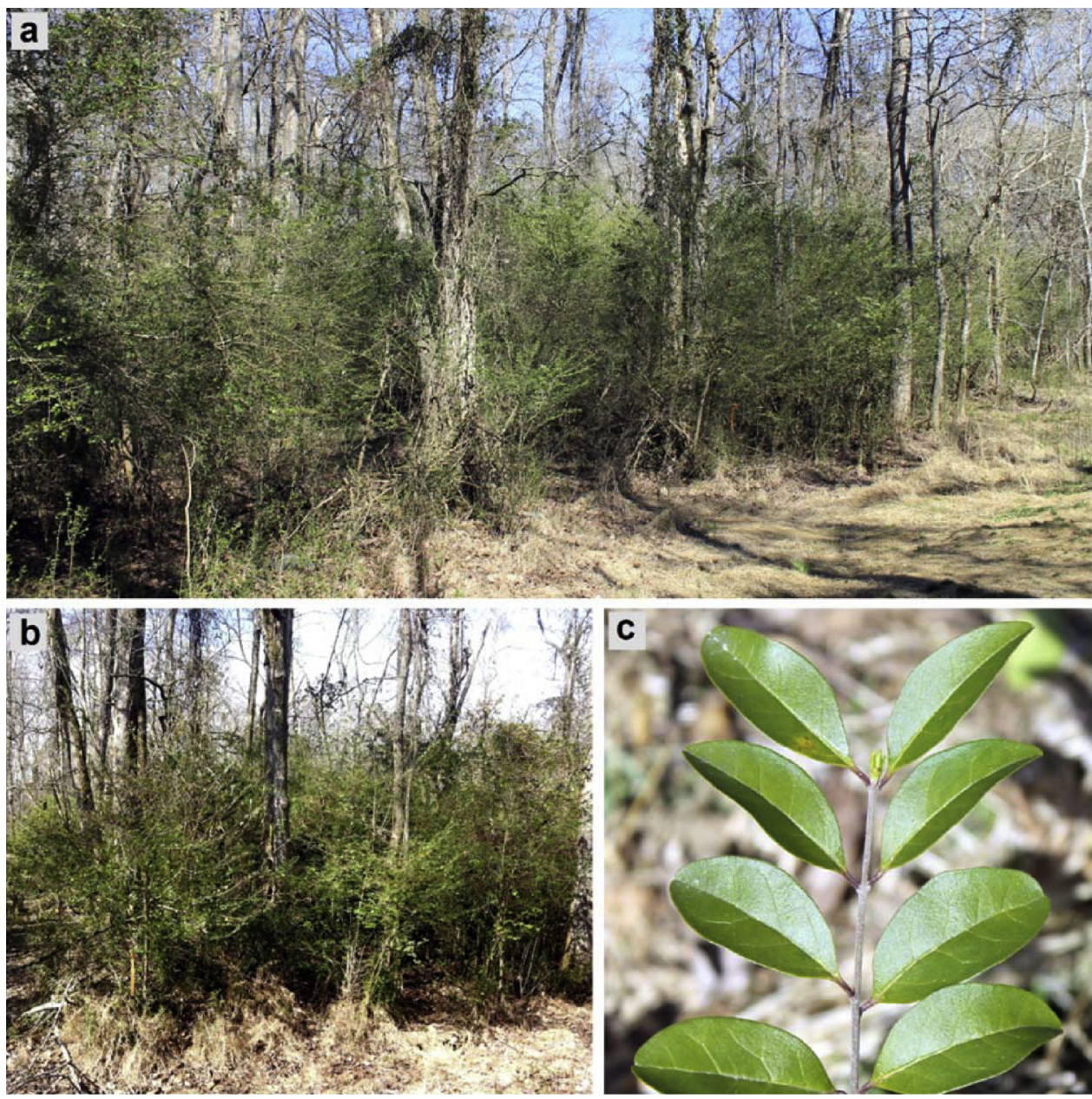

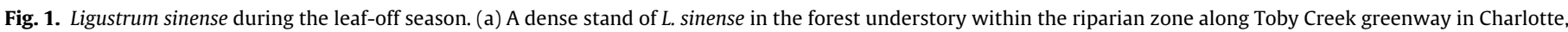
North Carolina, USA, (b) a dense monotypic stand of $L$. sinense, and (c) typical foliage exhibits thick leaves with a glossy upper surface and light green lower surface.

lowland field plots in the study system across urban, suburban, and rural forested landscapes. At each site, we established a $10 \times 10 \mathrm{~m}$ (0.01 ha) plot by defining a center point and recording coordinates using a Garmin GPSMAP 62s device. We used a modified Braun-Blanquet scale to collect presence/absence data following an assessment of abundance by estimating the percentage of the plot area occupied by aerial parts of $L$. sinense. We noted whether $L$. sinense was present or absent, and if present, collected data as percentage cover (up to $20 \%, 40 \%, 60 \%, 80 \%$, and $100 \%$ ) (Table 1 ).

\section{LiDAR data acquisition}

We obtained 1896 tiles of discrete return airborne LiDAR data covering Mecklenburg County from the GIS Mapping and Project Services of Charlotte-Mecklenburg County. Data were provided in the State Plane Coordinate System (NC FIPS 3200, NAD 1983, m)

Table 1

Distribution of $100 \mathrm{~m}^{2}$ field plots along urban-rural gradients.

\begin{tabular}{|c|c|c|c|c|c|c|}
\hline \multirow[t]{2}{*}{ Class } & \multicolumn{2}{|c|}{ County extent } & \multirow[t]{2}{*}{ Total } & \multicolumn{2}{|c|}{ Experimental extent ${ }^{\mathrm{a}}$} & \multirow[t]{2}{*}{ Total } \\
\hline & Presence & Absence & & Presence & Absence & \\
\hline Urban & 68 & 88 & 156 & 16 & 11 & 27 \\
\hline Suburban & 27 & 113 & 140 & 7 & 43 & 50 \\
\hline \multirow[t]{2}{*}{ Rural } & 4 & 46 & 50 & 0 & 4 & 4 \\
\hline & 99 & 247 & 346 & 23 & 58 & 81 \\
\hline
\end{tabular}

a Field data used in the analyses at the experimental extent. with each tile having dimensions $914.40 \mathrm{~m} \times 914.40 \mathrm{~m}$ (Fig. 2b). Pictometry International Corp. (Rochester, New York) acquired the data over six missions between April 11 and 14, 2012 using an Optech ALTM Gemini 3100 LiDAR system. The on-board GPS (global positioning system) data from the aircraft and concurrent groundbased station data were post-processed using Applanix POSPac v4.4 to generate a smoothed best estimate trajectory (SBET). Optech's DashMap software package was used to produce LiDAR point cloud data from the raw laser range data combined with SBET, and further processed in TerraMatch software to measure and apply small adjustments to the system's orientation angles in order to ensure proper alignment of data between flight lines. Additionally, TerraScan was used to classify returns as either ground or non-ground points and to ensure the quality of the classification. The sensor recorded four returns plus intensity with an average point spacing of $1 \mathrm{~m}$ between any two neighboring points over the study area.

\section{LiDAR data processing}

Topography and forest strata play a key role in the distribution and growth of understory plant invasions (Royo and Carson, 2006). We developed LiDAR metrics representing overstory and understory forest structure, and topography. We processed each LiDAR tile using the BCAL LiDAR tools, based on IDL programing language (BCAL LiDAR Tools, 2013), at $5 \mathrm{~m}$ resolution rasterized metrics for the entire county. Processing LiDAR data at $5 \mathrm{~m}$ spatial resolution allowed us to capture the variability within the plot while maintaining computational efficiency during the analysis (Singh et al., 
Table 2

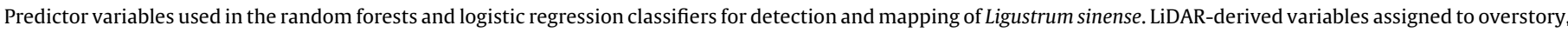
understory, topography, and overall vegetation characteristics types while IKONOS-derived variables are optical type.

\begin{tabular}{|c|c|c|}
\hline Variable type & Variable name & Description \\
\hline Overstory & $\begin{array}{l}H_{\mathrm{MAX}} \\
H_{\mathrm{PCT}(75-95)} \\
V_{\mathrm{HT} 3} \\
V_{\mathrm{HT} 4} \\
V_{\mathrm{STRATUM}(4-6)}\end{array}$ & $\begin{array}{l}\text { Height maximum } \\
\text { Height percentile } 75 \mathrm{th}, 90 \mathrm{th} \text {, and } 95 \mathrm{th} \\
\text { Vegetation height }>5 \mathrm{~m} \text { and } \leq 10 \mathrm{~m} \\
\text { Vegetation height }>10 \mathrm{~m} \\
\text { Percentage of vegetation returns in the height }>10 \mathrm{~m} \text { and } \leq 20 \mathrm{~m}, 20 \mathrm{~m} \text { and } \leq 30 \mathrm{~m} \text {, and }>30 \mathrm{~m}\end{array}$ \\
\hline Understory & $\begin{array}{l}H_{\text {MIN }} \\
H_{\text {PCT }(5-50)} \\
V_{\text {HT1 }} \\
V_{\text {HT2 }} \\
V_{\text {STRATUM(0-3) }}\end{array}$ & $\begin{array}{l}\text { Height minimum } \\
\text { Height percentile } 5 \mathrm{th}, 10 \mathrm{th}, 25 \mathrm{th} \text {, and } 50 \text { th (median) } \\
\text { Vegetation height }>0 \mathrm{~m} \text { and } \leq 1 \mathrm{~m} \\
\text { Vegetation height }>1 \mathrm{~m} \text { and } \leq 5 \mathrm{~m} \text { (understory vegetation) } \\
\text { Percentage of vegetation returns in the height range }>0 \mathrm{~m} \text { and } \leq 1 \mathrm{~m},>1 \mathrm{~m} \text { and } \leq 2.5 \mathrm{~m} \text {, and }>2.5 \mathrm{~m} \text { and } \leq 10 \mathrm{~m}\end{array}$ \\
\hline Topography & $\begin{array}{l}\text { ASP } \\
\mathrm{BE}_{\mathrm{AR}} \\
\mathrm{BE}_{\mathrm{GPD}} \\
\mathrm{BE}_{\mathrm{IMIN}} \\
\mathrm{BE}_{\mathrm{IMAX}} \\
\mathrm{BE}_{\mathrm{IMEA}} \\
\mathrm{BE}_{\mathrm{ISD}} \\
\mathrm{BE}_{\mathrm{Lmin}} \\
\mathrm{BE}_{\mathrm{Lmax}} \\
\mathrm{BE}_{\mathrm{Lmea}} \\
\mathrm{BE}_{\mathrm{LR}} \\
\mathrm{BE}_{\mathrm{SLPOSASP}} \\
\mathrm{BE}_{\mathrm{SLPSINASP}} \\
\mathrm{DEM} \\
\text { ERR } \\
\text { CrV } \\
H_{\mathrm{DE}} \\
N_{\text {LGR }} \\
\text { PGR } \\
\text { SLP } \\
\text { SRI } \\
\text { TMI } \\
\text { TRI }\end{array}$ & $\begin{array}{l}\text { Aspect } \\
\text { Bare earth absolute roughness } \\
\text { Ground point density } \\
\text { Bare earth intensity minimum } \\
\text { Bare earth intensity maximum } \\
\text { Bare earth intensity mean } \\
\text { Bare earth intensity standard deviation } \\
\text { Bare earth elevation minimum } \\
\text { Bare earth elevation maximum } \\
\text { Bare earth elevation mean } \\
\text { Bare earth local roughness } \\
\text { Bare earth slope cosine aspect } \\
\text { Bare earth slope sine aspect } \\
\text { Digital elevation model } \\
\text { Elevation relief ratio } \\
\text { Curvature surface } \\
\text { Hill-shade } \\
\text { Number of LiDAR ground returns } \\
\text { Percentage ground return } \\
\text { Slope surface (degree) } \\
\text { Solar radiation index } \\
\text { Topographic moisture index } \\
\text { Topographic roughness index }\end{array}$ \\
\hline $\begin{array}{l}\text { Overall vegetation } \\
\text { characteristics }\end{array}$ & $\begin{array}{l}H_{\mathrm{AAD}} \\
H_{\mathrm{CV}} \\
H_{\mathrm{IQR}} \\
H_{\mathrm{KUR}} \\
H_{\mathrm{MAD}} \\
H_{\mathrm{MEAN}} \\
H_{\mathrm{RNG}} \\
H_{\mathrm{SD}} \\
H_{\mathrm{SEE}} \\
H_{\mathrm{TEX}} \\
H_{\mathrm{VAR}} \\
I_{\mathrm{ALL}} \\
I_{\mathrm{MIN}} \\
I_{\mathrm{MAX}} \\
I_{\mathrm{MEAN}} \\
I_{\mathrm{SD}} \\
N_{\mathrm{LR}} \\
N_{\mathrm{LVR}} \\
V_{\mathrm{TVD}} \\
\mathrm{VC}_{\mathrm{TYPE}} \\
\mathrm{VI}_{\mathrm{MIN}} \\
\mathrm{VI}_{\mathrm{MAX}} \\
\mathrm{VI}_{\mathrm{MEAN}} \\
\mathrm{VI} \mathrm{SD}_{\mathrm{SD}}\end{array}$ & $\begin{array}{l}\text { Height average absolute deviation } \\
\text { Height coefficient of variation } \\
\text { Height interquartile range } \\
\text { Height kurtosis } \\
\text { Height median absolute deviation } \\
\text { Height mean } \\
\text { Height range } \\
\text { Height standard deviation } \\
\text { Height skewness } \\
\text { Height texture } \\
\text { Height variance } \\
\text { Intensity surface overall } \\
\text { Intensity surface minimum } \\
\text { Intensity surface maximum } \\
\text { Intensity surface mean } \\
\text { Intensity surface standard deviation } \\
\text { Number of LiDAR returns } \\
\text { Number of LiDAR vegetation returns } \\
\text { Total vegetation density } \\
\text { Vegetation cover type (deciduous, evergreen and mixed) } \\
\text { Vegetation intensity minimum } \\
\text { Vegetation intensity maximum } \\
\text { Vegetation intensity mean } \\
\text { Vegetation intensity standard deviation }\end{array}$ \\
\hline Optical & $\begin{array}{l}\text { Texture } \\
\text { ARVI } \\
\text { MSAVI } \\
\text { IHS } \\
\text { EVI } \\
\text { Pan }\end{array}$ & $\begin{array}{l}\text { Texture (contrast, homogeneity, variance, and correlation) } \\
\text { Atmospherically resistant vegetation index } \\
\text { Modified soil adjusted vegetation index } \\
\text { Hue intensity and saturation } \\
\text { Enhanced vegetation index } \\
\text { Pan-sharpened bands (three visible and one infrared) }\end{array}$ \\
\hline
\end{tabular}




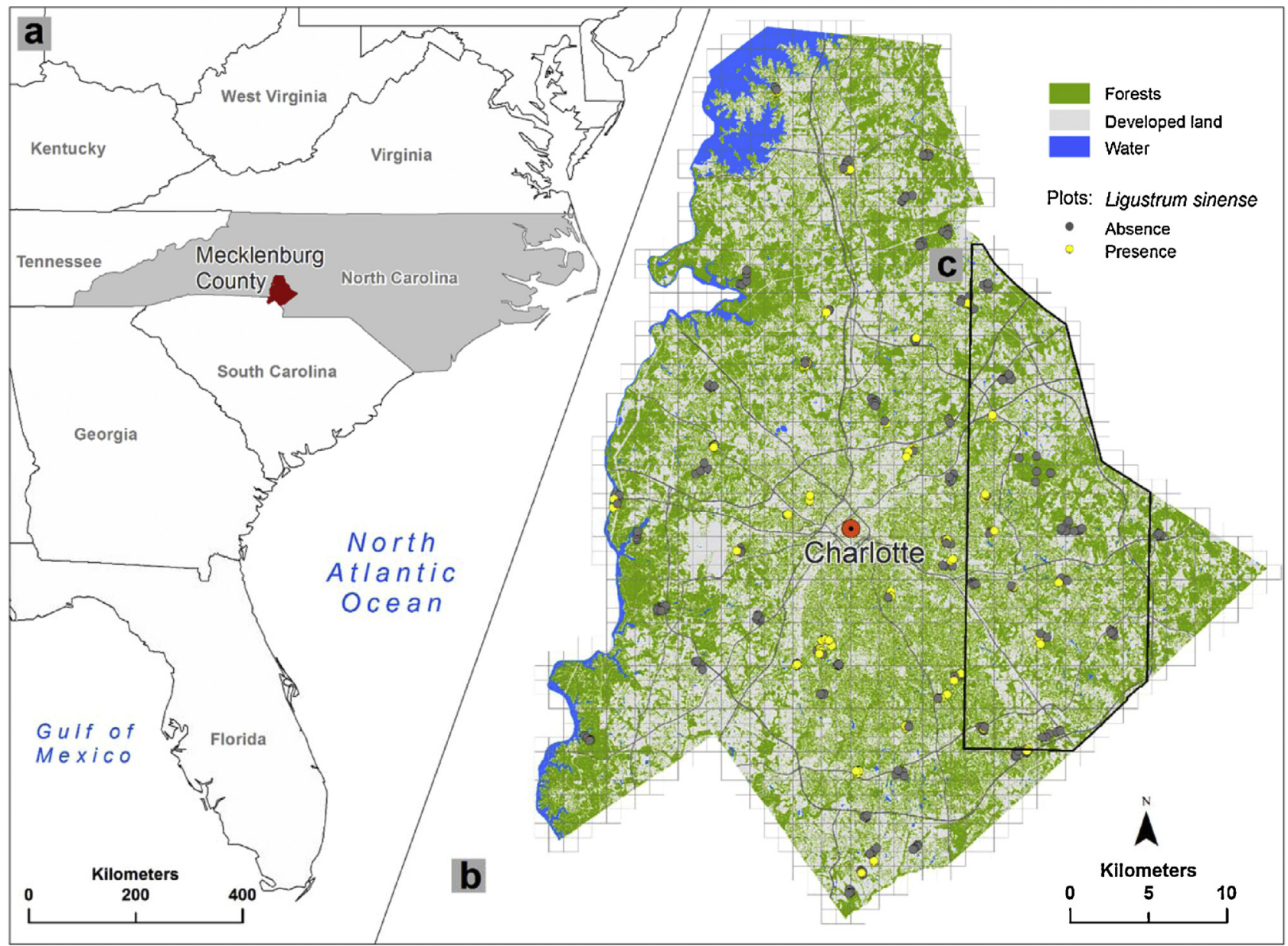

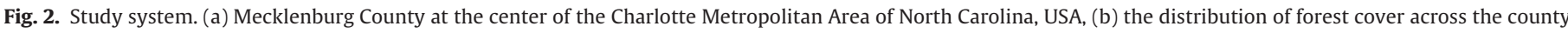

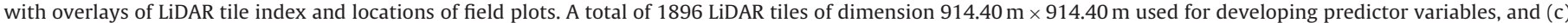
the extent of IKONOS coverage.

2012). To account for forest vertical structures in the analyses, we divided forest into four vertical strata $(\leq 1 \mathrm{~m} ;>1-\leq 5 \mathrm{~m} ;>5-\leq 10 \mathrm{~m}$; and $>10 \mathrm{~m}$ ) following the height range of $L$. sinense. LiDAR data collected in the leaf-off season vary significantly both in point density and intensity values for different forest types such that contrast among different forest strata and topography is emphasized. We converted LiDAR intensity into various vegetation and topography intensity metrics. We also developed height percentile metrics to represent the proportion of vegetation below a given percentile. For example, the 99th percentile defines a measure of the maximum height, whereas the remaining percentiles quantify variation in height across the vegetation profile (Jaskierniak et al., 2011).

We developed indices using a LiDAR-derived digital elevation model (DEM) to characterize moisture content and site conditions. Indices include an integrated moisture index (IMI), an elevation to relief ratio (ERR), a topographic roughness index (TRI), and a solar radiation index (SRI). An IMI with increasing values indicates increasing moisture accumulation and retention (Iverson et al., 1997). The ERR index measures the extent to which topography has been opened up by erosion (Martinuzzi et al., 2009). The TRI is a measure of variability in the landscape surface and a proxy for disturbances (Stambaugh and Guyette, 2008). The SRI affects biological processes that influence species distributions across landscapes (Keating et al., 2007). We used a three-band composite dataset containing a canopy height model, a normalized digital surface model, and a differenced surface model of these two to classify forested landscapes into deciduous and evergreen types (Singh et al., 2010). We created sixty-six variables from LiDAR, consisting of 43 canopy and 23 topographic metrics at the county extent (Table 2). We further post-processed these metrics using a mask of vegetation cover to exclude developed land cover types from forested landscapes.

\section{IKONOS data acquisition}

We acquired a cloud-free multispectral IKONOS image from the leaf-off season dated February 21, 2010, covering a portion of Mecklenburg County (Fig. 2c) (hereafter referred to as "experimental extent"). The image consists of three pan-sharpened visible bands (blue, 0.45-0.52 $\mu \mathrm{m}$; green, 0.51-0.60 $\mu \mathrm{m}$; red, 0.63-0.70 $\mu \mathrm{m}$ ) and one near infrared band (nir, $0.76-0.85 \mu \mathrm{m}$ ) at $1 \mathrm{~m}$ spatial resolution. We projected the four-band composite image into the State Plane Coordinate System (NC FIPS 3200, NAD 1983, m). The selection of leaf-off IKONOS images facilitated spectral discrimination between L. sinense and neighboring deciduous trees. We applied radiometric correction to ground reflectance by applying a simple dark pixel subtraction method. We co-registered calibrated IKONOS data to the LiDAR intensity surface model by creating 15 landmark control points using the same features on both images. We applied an affine transformation based RST (rotation, scaling, and translation) algorithm to warp image followed by nearest neighbor resampling method. On average, a positional difference of the same features between the two images was less than one-fourth of the pixel. 


\section{IKONOS data processing}

We developed fourteen spectral features, including a pan-sharpened, four-band image, a three-band hue-intensitysaturation (HIS) image, four texture images (contrast, homogeneity, variance, and correlation), and three vegetation indices: (1) enhanced vegetation index (EVI), (2) modified soil adjusted vegetation index (MSAVI), and (3) the atmospherically-resistant vegetation index (ARVI). Studies have demonstrated the efficacy of pan-sharpened imagery in the classification of forest tree species in urban areas, estimation of vegetation cover, detection of disturbance severity and canopy heterogeneity, and for understanding the spatiotemporal distributions of forest structural and dynamic variables in the tropical forest (Carleer and Wolff, 2004; $\mathrm{Pu}, 2011$ ). We transformed the pan-sharpened four-band image to HIS, and texture images. Texture images are useful for retrieving forest structure variables and distinguishing subtle differences in vegetation types (Franklin et al., 2001; Kayitakire et al., 2006). The EVI is suitable for detecting changes in areas of high biomass. The MSAVI distinguishes areas with a high degree of exposed soil surface. The ARVI, being less sensitive to atmospheric effects (aerosols), is useful for measuring and monitoring plant growth, vegetation cover, and biomass production. Finally, we resampled these features to $5 \mathrm{~m}$ resolution to match the spatial grain of the LiDAR-derived variables to facilitate comparisons.

\section{Datasets and modeling schema}

To understand the contribution of forest structure in detection and mapping of $L$. sinense, we categorized the LiDAR-derived variables into overstory, understory, topography, and overall vegetation characteristics variable types and assigned IKONOS spectral features to the optical types (Table 2). We used the description of variables and their established applications in forestry-related studies for the purpose of categorization (Asner et al., 2008; Falkowski et al., 2009; Hudak et al., 2008; Jaskierniak et al., 2011; Martinuzzi et al., 2009). Using the five 'variable types', we developed thirty-one unique combinations of models at the IKONOS experimental extent (Fig. 2c; Table 3), and then further applied the RF (Breiman, 2001) classifier to analyze relative contributions of sensors and forest landscape structures in detection $L$. sinense. Finally, we compared the top performing model developed from selected predictor variables (PVs) using the RF classifier to the best parametric model developed from LR (Orka et al., 2012), and used the best overall model to map the probability of $L$. sinense occurrence across the heterogeneous county extent Fig. 3.

\section{Statistical analysis}

We implemented the RF and LR classifiers in the IDL (Waske et al., 2012) and R programming environment (R Core Team, 2013), respectively. In order to account for the time lag between field data and remotely sensed data, we performed visual assessment of the field data collected prior 2012 using LiDAR canopy cover to eliminate those field plots affected by forest loss.

Traditional statistical methods do not address nonlinear complex interactions among high-dimensional remote sensing variables (Cutler et al., 2007). To overcome these limitations, we used a non-parametric RF classifier, a decision-tree-based ensemble classifier, which has proven effective in the classification of high-dimensional remote sensing and ecological data (Cutler et al., 2007; Goetz et al., 2010; Martinuzzi et al., 2009). We selected the RF classifier based on: (1) its robustness and accurate performance on complex datasets with an array of input variables (higher dimensionality) (Guo et al., 2011; Stumpf and Kerle, 2011), (2) its ability to determine significant variables in the classification, and (3) a waiver from cross-validation as it generates an internal
Table 3

Model accuracy estimates using random forests classifier at the experimental extent.

\begin{tabular}{|c|c|c|c|c|}
\hline Models & $\begin{array}{l}\text { Accuracy estimate }^{a} \\
\text { F-1 measure } \pm\end{array}$ & Kappa & Specificity & Sensitivity \\
\hline$M_{\mathrm{Os}}$ & 57.16 & 0.239 & 0.636 & 0.754 \\
\hline$M_{\mathrm{Us}}$ & 41.34 & 0.000 & 0.000 & 0.722 \\
\hline$M_{\mathrm{To}}$ & 60.04 & 0.308 & 0.636 & 0.790 \\
\hline$M_{\mathrm{Ot}}$ & 47.46 & 0.086 & 0.417 & 0.734 \\
\hline$M_{\mathrm{Op}}$ & 42.58 & 0.019 & 0.125 & 0.724 \\
\hline$M_{\text {OsUs }}$ & 43.48 & 0.038 & 0.167 & 0.724 \\
\hline$M_{\text {OsTo }}$ & 57.05 & 0.260 & 0.488 & 0.767 \\
\hline$M_{\text {UsTo }}$ & 55.70 & 0.213 & 0.448 & 0.742 \\
\hline$M_{\mathrm{OsOt}}$ & 43.25 & 0.034 & 0.250 & 0.727 \\
\hline$M_{\mathrm{UsOt}}$ & 42.69 & 0.000 & 0.125 & 0.725 \\
\hline$M_{\mathrm{ToOt}}$ & 52.93 & 0.213 & 0.375 & 0.746 \\
\hline$M_{\mathrm{OsOp}}$ & 48.61 & 0.149 & 0.625 & 0.730 \\
\hline$M_{\text {UsOp }}$ & 41.63 & 0.000 & 0.000 & 0.722 \\
\hline$M_{\mathrm{ToOp}}$ & 55.39 & 0.270 & 0.604 & 0.760 \\
\hline$M_{\mathrm{OtOp}}$ & 47.55 & 0.101 & 0.500 & 0.733 \\
\hline$M_{\text {OsUsOt }}$ & 43.79 & 0.038 & 0.375 & 0.739 \\
\hline$M_{\text {UsToOt }}$ & 55.67 & 0.255 & 0.500 & 0.763 \\
\hline$M_{\text {OsToOt }}$ & 55.93 & 0.244 & 0.563 & 0.758 \\
\hline$M_{\text {OsUsTo }}$ & 55.53 & 0.236 & 0.388 & 0.765 \\
\hline$M_{\text {OsUsOp }}$ & 41.63 & 0.014 & 0.000 & 0.735 \\
\hline$M_{\text {OsToOp }}$ & 56.09 & 0.270 & 0.625 & 0.762 \\
\hline$M_{\text {UsToOp }}$ & 54.86 & 0.250 & 0.475 & 0.758 \\
\hline$M_{\text {OsOtOp }}$ & 48.28 & 0.129 & 0.500 & 0.733 \\
\hline$M_{\text {UsOtOp }}$ & 46.68 & 0.100 & 0.250 & 0.728 \\
\hline$M_{\text {ToOtOp }}$ & 53.51 & 0.184 & 0.469 & 0.802 \\
\hline$M_{\text {OsUsToOt }}$ & 52.69 & 0.180 & 0.375 & 0.751 \\
\hline$M_{\text {OsUsToOp }}$ & 51.94 & 0.205 & 0.500 & 0.747 \\
\hline$M_{\text {OsUsOpOt }}$ & 42.97 & 0.030 & 0.125 & 0.739 \\
\hline$M_{\text {OsToOpot }}$ & 55.68 & 0.238 & 0.531 & 0.749 \\
\hline$M_{\text {UsToOpOt }}$ & 54.32 & 0.196 & 0.542 & 0.759 \\
\hline$M_{\mathrm{ALL}}$ & 54.79 & 0.229 & 0.500 & 0.757 \\
\hline
\end{tabular}

$\pm \mathrm{F}$-1 measure - the harmonic mean of precision and recall.

a 10 -fold cross-validated accuracy estimate.

unbiased estimate of test error (Cutler et al., 2007). The RF classifier provides estimates of variable importance in the classification to assist with reducing data dimensionality. The classifier operates by growing a large number of individual decision trees from randomized subsets of training samples to maximum size without pruning, and then selecting only the best split among a random subset at each node (Falkowski et al., 2009; Prasad et al., 2006). The optimal classification is then determined by selecting the most common classification results at each node within the group of multiple decision trees (Breiman, 2001). Due to the randomness, the bias of RF usually increases, but its variance also decreases due to averaging, therefore constructing the most parsimonious classification model that retains the highest classification accuracy (Cutler et al., 2007; Goetz et al., 2010). For comparison, and due to the binary nature of the output, we also applied the LR classifier to plot level datasets. This approach offers a robust discriminant function without assuming a specific distribution in the input variables.

We applied the LR classifier to analyze the presence of $L$. sinense, in which field-collected privet occurrence data served as the response variable and remote sensing covariates as PVs. Our selection of LR is based on its flexibility related to key statistical assumptions (linearity, normality, and homoscedasticity), and the straightforward interpretation of results based on odds ratios and statistical hypothesis testing. We modeled the logit of the presence of $L$. sinense as:

$y=\log _{e}\left[\frac{P}{(1-P)}\right]=\operatorname{logit}(P)=\beta_{0}+\beta_{1} x_{1}+\ldots+\beta_{k} x_{k}$

where $y$ is a linear combination function of included PVs $x_{1}, \ldots x_{k}$, the parameters $\beta_{0}+\beta_{1}, \ldots+\beta_{k}$ are the regression coefficients to be estimated, $P$ is the probability of the occurrence of $L$. sinense, and $\operatorname{logit}(P)$ is the odds ratio. 

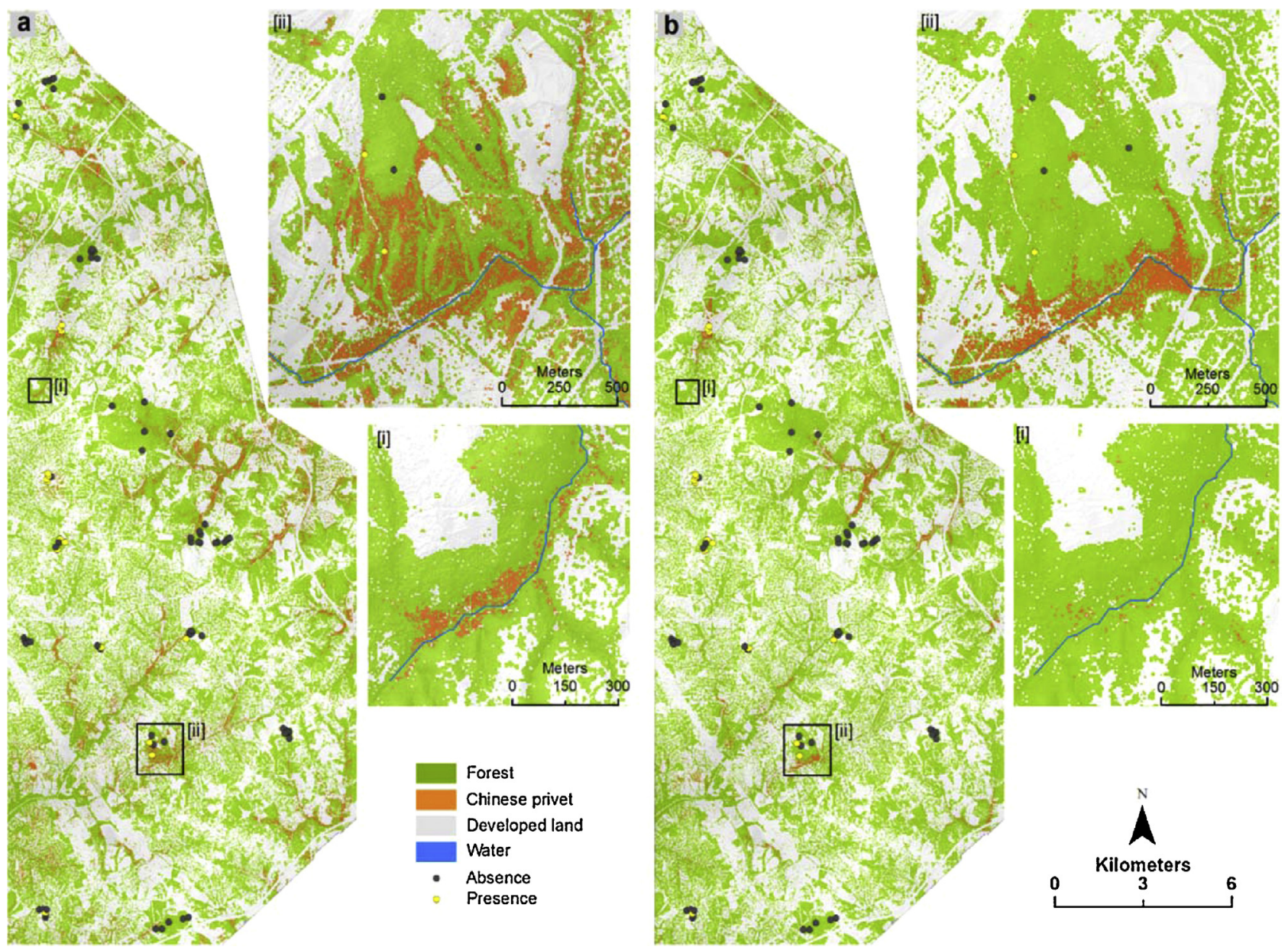

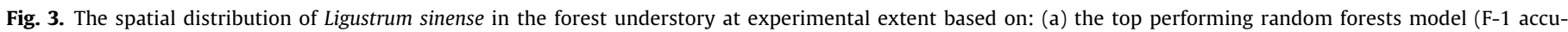
racy $=69.90 \%$ ) developed using selected predictor variables with high variable importance, and (b) a parsimonious logistic regression model (F-1 accuracy $=54.50 \%$ ).

We used the variance inflation factor (VIF) $\leq 10$ for the identification and removal of collinear PVs, and we applied the backward elimination technique by deleting one predictor variable for each iteration until no further improvement in the Akaike's information criterion (AIC) was observed (Orka et al., 2012). Since AIC penalizes over fitting a model, the lowest AIC value is ideal for selecting a model from a set of models for a given set of data. We used a maximized sum of specificity and sensitivity criterion (MST - maximized sum threshold) for selecting the threshold of occurrence for L. sinense detection. The MST is the value that maximizes the sum of specificity and sensitivity in the model, and may offer a number of cutoffs that do nearly as well. Once an optimal LR was established, we applied it to the entire dataset to produce a categorical map of presence and absence of $L$. sinense.

\section{Evaluation of model performance}

We evaluated model performance by computing resubstitution and 10 -fold cross-validation ( $k$-fold CV) estimates for all models from RF and LR classifiers using F-1 measure (sensitivity, specificity, and kappa), and the area under the receiver operating characteristic curve (ROC). The area under the ROC curve ranges from 0 to 1 (none correctly classified to all correctly classified) and provides a quantitative measure of model performance. We obtained the ROC by plotting the true positive proportion of correctly predicted presences (sensitivity) on the $Y$-axis against the false positive proportion of correctly predicted absences (specificity) on the $X$-axis. Since the RF classifier provides a reliable error estimate using data that is randomly withheld from each iteration of tree development (the "out-of-bag" portion), an accuracy assessment using independent testing data is not required (Lawrence et al., 2006). However, for the purpose of model comparison and analytical robustness, we computed a $k$-fold $\mathrm{CV}$ by dividing the field data into ten equal sets, where nine sets were input for training and one set for testing, and repeated this procedure ten times (Cutler et al., 2007).

\section{Results}

\section{Understory detection and mapping performance}

The LiDAR-derived PVs produced the highest accuracy estimates, outperforming both IKONOS alone and the integration of LiDAR and IKONOS data (Figs. 3 and 7). The RF classifier, with selected PVs (10 variables) at experimental and county extents (Fig. 4a and b), performed substantially better with higher accuracy estimates compared to the LR classifier (Fig. 5), while the LR classifier showed less variability between resubstitution and cross-validated accuracy estimates. The RF model at the experimental extent produced the highest resubstitution kappa of $64.8 \%$ (Fig. 3), improving on the LR model by $31.1 \%$ with a moderate gain of $6.2 \%$ compared to the county extent (Tables 3 and 4 ). The $k$ fold $\mathrm{CV}$ revealed the robustness of the RF classifier by producing a similar kappa ( $1 \%$ difference) estimate at both extents. In addition, the kappa estimate was $21 \%$ and $40 \%$ higher as compared to the model from the LR classifier and models created by the com- 
a
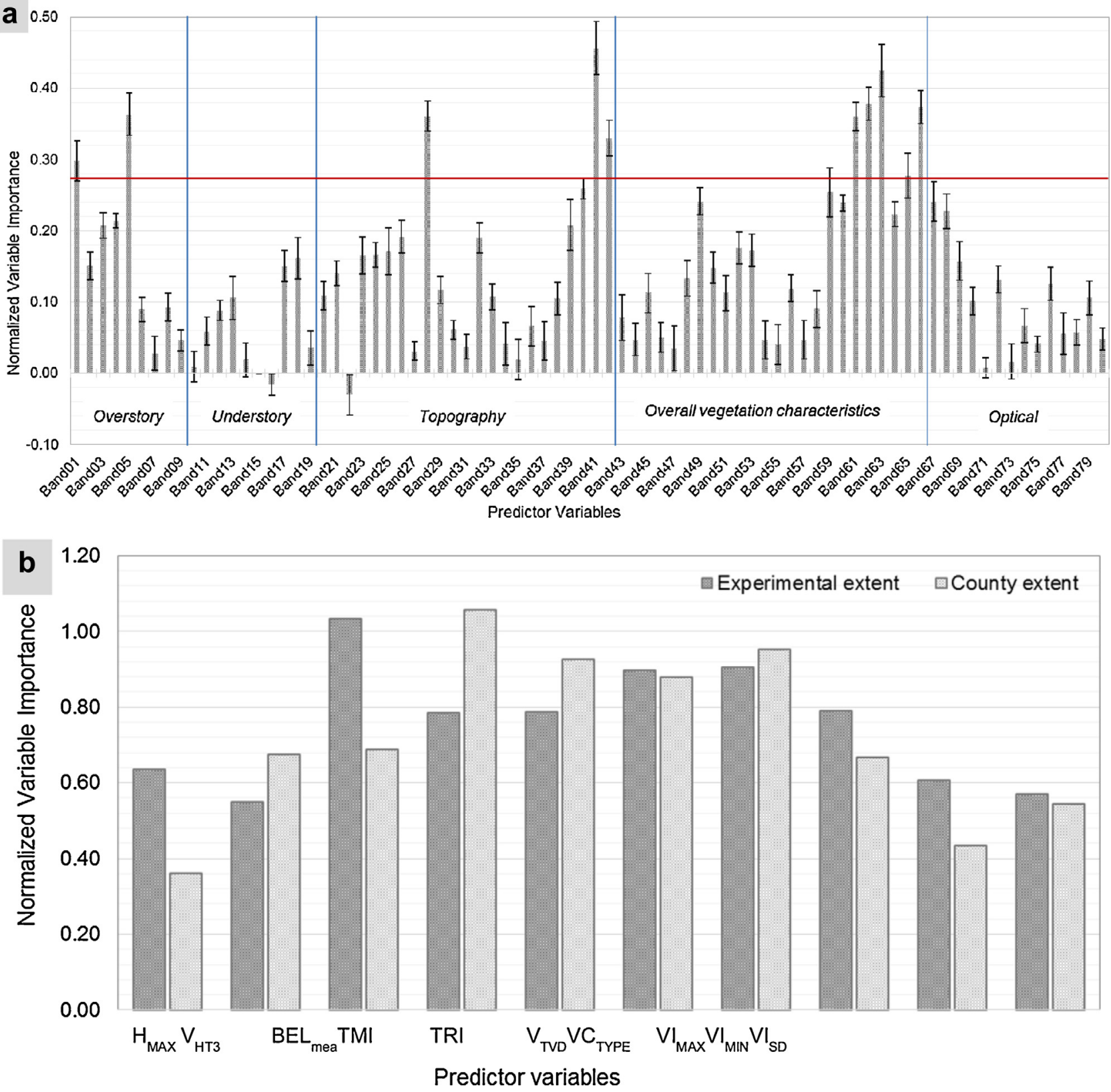

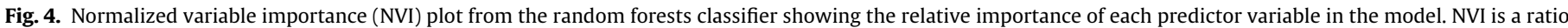

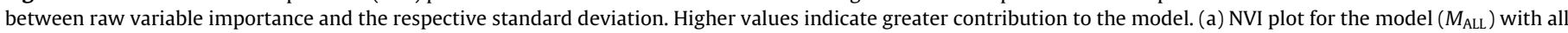
predictor variables at experimental extent, and (b) NVI plot for models developed from selected predictor variables at experimental and county extents.

\section{Table 4}

Accuracy metrics for top performing models with observed and predicted frequencies at the experimental and county extents.

\begin{tabular}{|c|c|c|c|c|c|c|c|c|c|}
\hline \multirow[b]{3}{*}{ Observed } & \multicolumn{6}{|c|}{ Experimental extent } & \multirow{2}{*}{\multicolumn{3}{|c|}{$\begin{array}{l}\text { County extent } \\
\text { RF } \\
\text { Predicted }\end{array}$}} \\
\hline & \multicolumn{3}{|l|}{$\begin{array}{l}\mathrm{RF} \\
\text { Predicted }\end{array}$} & \multicolumn{3}{|l|}{$\begin{array}{l}\text { LR } \\
\text { Predicted }\end{array}$} & & & \\
\hline & Presence & Absence & $\%$ Correct & Presence & Absence & $\%$ Correct & Presence & Absence & $\%$ Correct \\
\hline Presence & 11 & 9 & 55.00 & 15 & 20 & 42.90 & 92 & 31 & 74.80 \\
\hline Absence & 0 & 61 & 100.00 & 5 & 41 & 89.10 & 35 & 187 & 84.20 \\
\hline Overall \% correct & & & 88.89 & & & 69.14 & & & 80.87 \\
\hline Accuracy & F-1 measures: & 71.00 & & F-1 measures: & 54.50 & & F-1 measures: & 73.60 & \\
\hline estimates & Kappa: & 0.648 & & Kappa: & 0.337 & & Kappa: & 0.586 & \\
\hline & Sensitivity: & 1.000 & & Sensitivity: & 0.750 & & Sensitivity: & 0.724 & \\
\hline & Specificity: & 0.871 & & Specificity: & 0.672 & & Specificity: & 0.858 & \\
\hline & AUC: & 0.936 & & AUC: & 0.787 & & AUC: & 0.791 & \\
\hline 10-fold & F-1 measures: & 61.55 & & F-1 measures: & 53.30 & & F-1 measures: & 67.37 & \\
\hline cross-validation & Kappa: & 0.537 & & Kappa: & 0.331 & & Kappa: & 0.547 & \\
\hline
\end{tabular}

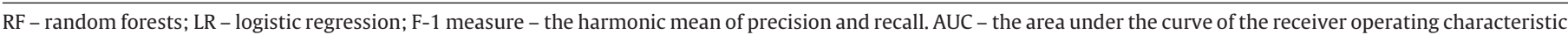


(a)

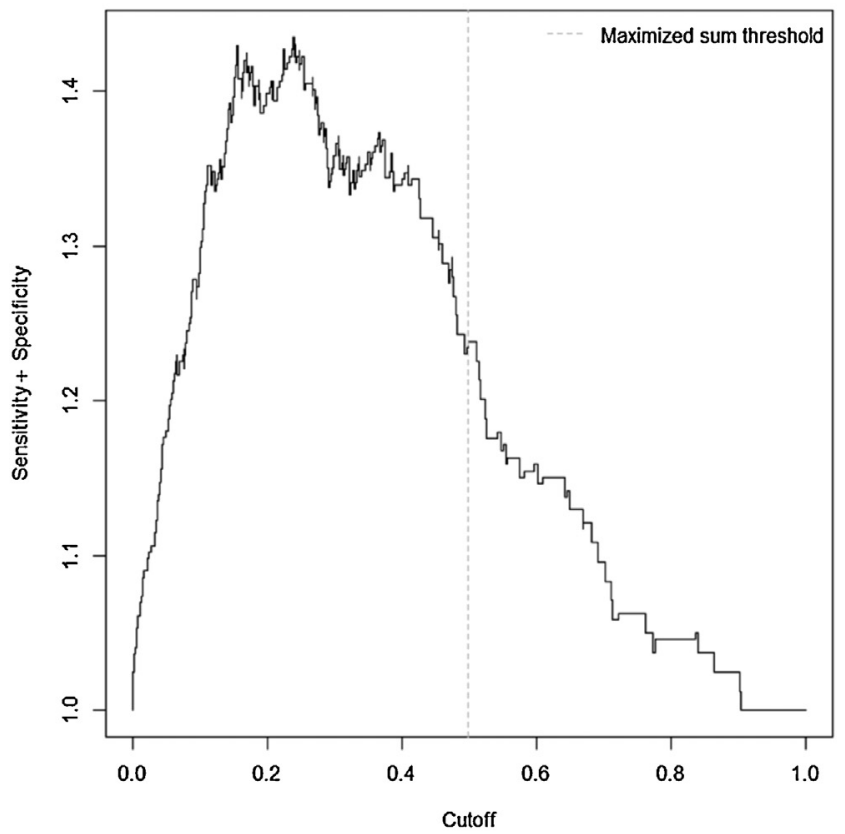

(b)

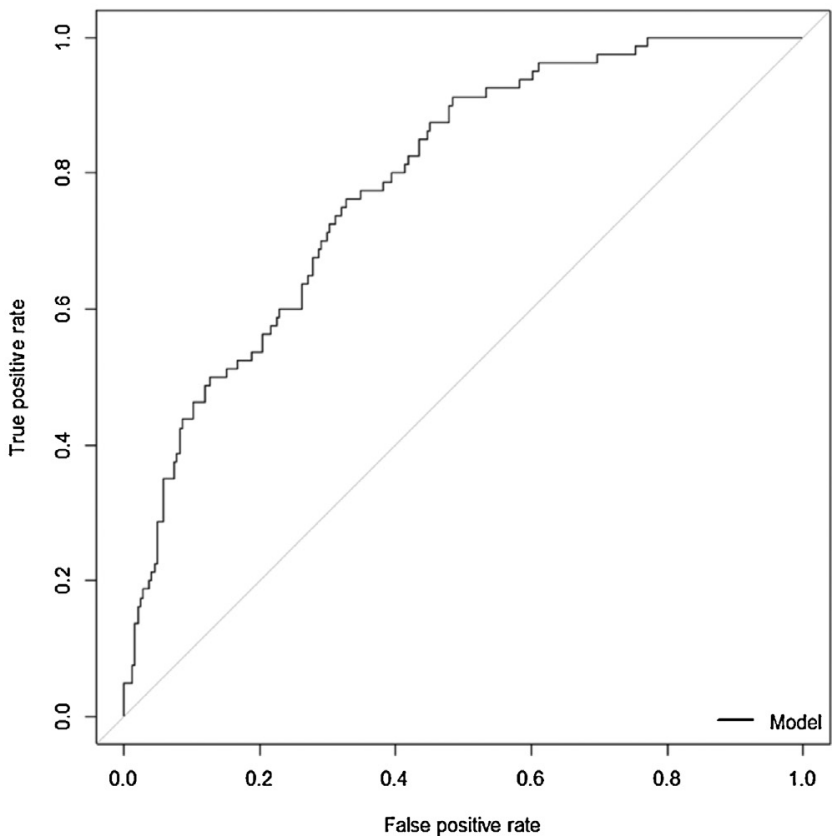

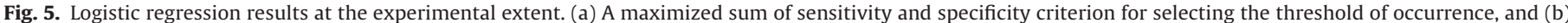

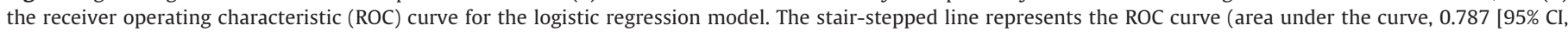
$0.74-0.83])$.
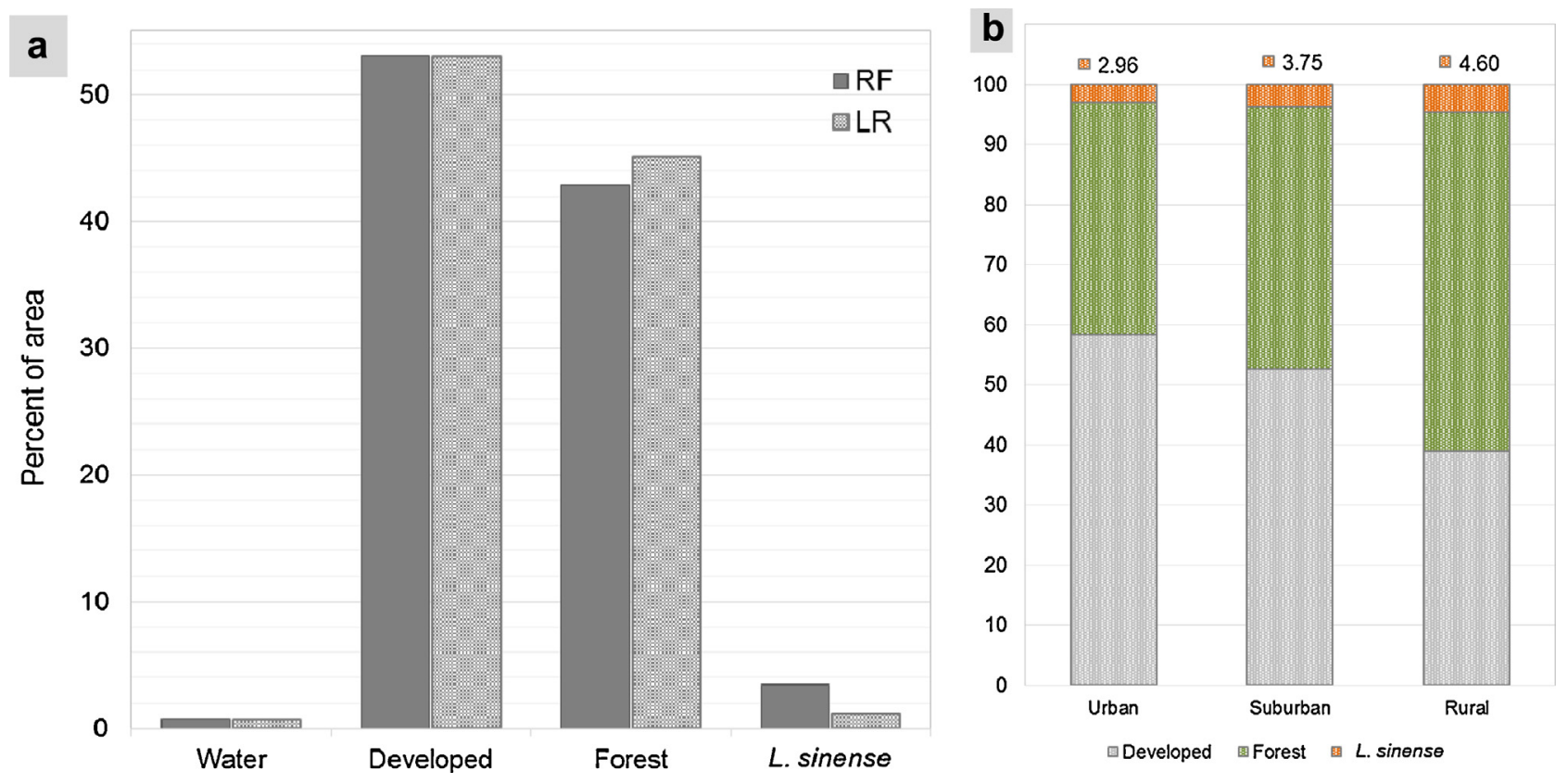

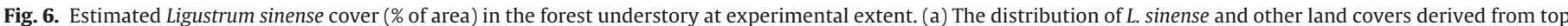
performing random forests (RF) and logistic regression (LR) models, and (b) the proportions of $L$. sinense cover along the urban-rural gradient.

bination of variable type using the RF classifier, respectively Fig. 5 (Table 4). The F- 1 estimate between resubstitution and $k$-fold CV varies on average $7.84 \%$ using the RF classifier compared to $1.2 \%$ using LR. The RF classifier predicted nearly three times the area of $L$. sinense spread in the understory of forests at the experimental extent compared to the LR classifier (Fig. 6a). The ratio of $L$. sinense to forest cover is nearly consistent across urban-rural gradients. However, the ratio of $L$. sinense to developed land cover in rural areas is $71 \%$ higher than in suburban areas, and $140 \%$ higher than in urban areas (Fig. 6b). The estimated sensitivities across the models, created by the combination of variable type, are relatively higher $\geq 0.72$, than specificities, which differ significantly except at the county extent where sensitivity is lower than specificity. However, with higher positive and negative productivity (ratio between true positive/negative and total positive/negative), the RF classifier performed substantially better at the county extent than at the experimental extent at detecting invasion. 


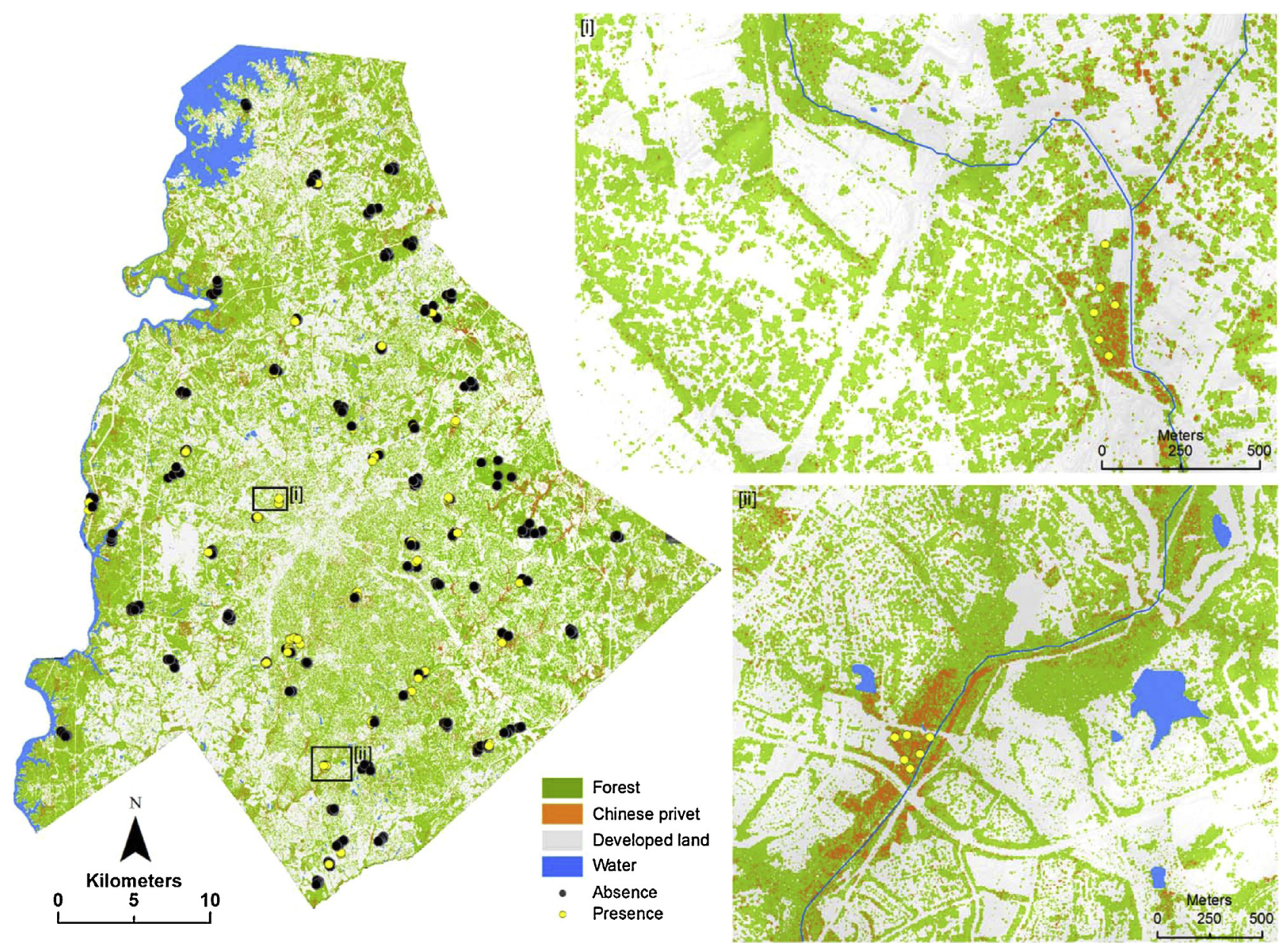

Fig. 7. The spatial distribution of Ligustrum sinense using the random forests classifier in the forest understory at the county extent.

\section{Relative contribution of IKONOS imagery and LiDAR data}

The F-1 and kappa estimates obtained from RF classification of optical PVs were only $1.25 \%$ and $1.9 \%$ higher, respectively, than the understory model, and contributed only marginally to improvements in overall accuracy estimates when combined with overall vegetation characteristics and understory PVs (Table 3). However, the IKONOS-derived PVs when analyzed together with the other LiDAR PVs did not improve classification accuracy estimates of detection and mapping $L$. sinense. Among the optical PVs, texture contributed slightly to improved detection when combined with overall vegetation characteristics while no other optical PVs were significant in the top performing RF and LR analysis.

\section{Contributions of forest landscape structures}

The topography PVs alone produced the highest accuracy estimates and contributed more to detection of $L$. sinense than other variable types across all models created by the combination of variable type using the RF classifier at the experimental extent. The F-1 estimate was $11.4 \%$ higher than average estimates obtained from other variable types alone, followed by overstory and overall vegetation characteristics (Table 3 ). Gains in accuracies did not improve with increasing numbers of variable types except for a slight improvement of $\geq 0.2$ kappa with the topography PVs. However, the RF variable importance plot of the $M_{\mathrm{ALL}}$ model (Fig. 4a) produced a higher number of PVs from overall vegetation charac- teristics contributing in the overall accuracy estimates followed by the topography and overstory variable types. The LR analysis also identified similar sets of significant variable types with the exception of understory ( $V_{\text {STRATUM-1 }}$ ) (Table 5). Two PVs: TMI and $\mathrm{VI}_{\mathrm{SD}}$, are significant in both the top performing models from RF classifier and model from the LR classifier. LiDAR intensity-derived forest landscape variables $\left(\mathrm{VI}_{\mathrm{MEAN}} / \mathrm{VI}_{\mathrm{MAX}}\right.$ and $\left.\mathrm{VI}_{\mathrm{MIN}}\right)$ contributed in both top performing RF and LR models. However, the lower performance suggests that the LR classifier was unable to address adequately some nonlinear structure for matching or higher accuracy estimates. The LR classifier revealed the magnitude and direction of PVs' contribution in the detection of $L$. sinense. Examination of the RF variable importance plots showed that in addition to the TMI, three PVs (topographic roughness index, vegetation density and forest cover types) contributed considerably to improved detection with higher accuracy estimates at both experimental and county extents (Fig. 4b).

\section{Large-area assessment of $L$. sinense}

The higher performance of LiDAR PVs using the RF classifier encouraged us to evaluate county level field data for improved detection of $L$. sinense. Our analysis produced similar $k$-fold CV kappa estimates with only slight variation in resubstitution accuracy estimates. Use of county level field data increased the positive, and negative predictive ratio by $33 \%$ as compared to the ratio at the experimental extent accompanied by a $13.4 \%$ difference between 
Table 5

Parameters and fit statistics for logistic regression model.

\begin{tabular}{|c|c|c|c|c|c|c|c|}
\hline Variable type & Predictor & Description & $\beta$ & SE $\beta$ & $z$ & $p$ & $\begin{array}{l}e \beta \\
\text { (odds ratio) }\end{array}$ \\
\hline & Constant & & -0.933 & 0.602 & -1.551 & 0.1208 & NA \\
\hline Understory & $V_{\text {STRATUM-1 }}$ & Percentage of vegetation returns & 0.035 & 0.014 & 2.470 & 0.0135 & 1.036 \\
\hline \multirow[t]{2}{*}{ Topography } & $B E_{I S D}$ & Bare earth intensity standard deviation & -0.051 & 0.022 & -2.308 & 0.0210 & 0.950 \\
\hline & TMI & Topographic moisture index & 0.014 & 0.003 & 4.558 & $<0.0001$ & 1.014 \\
\hline Overall vegetation & $H_{\text {KUR }}$ & Height kurtosis & -0.612 & 0.279 & -2.188 & 0.0287 & 0.542 \\
\hline \multirow[t]{3}{*}{ characteristics } & $I_{\mathrm{ALL}}$ & Intensity surface overall & -0.013 & 0.004 & -2.924 & 0.0035 & 0.987 \\
\hline & $\mathrm{VI}_{\text {MEAN }}$ & Vegetation intensity mean & -0.459 & 0.170 & -2.695 & 0.0070 & 0.631 \\
\hline & $\mathrm{VI}_{\mathrm{SD}}$ & Vegetation intensity standard deviation & 0.005 & 0.002 & 2.012 & 0.0442 & 1.005 \\
\hline Test & & & $X^{2}$ & & df & & $P$ \\
\hline \multirow[t]{2}{*}{ Overall model fit } & & Likelihood ratio test & 68.356 & & 7 & & $<0.0001$ \\
\hline & & Wald test & 13.900 & & 2 & & 0.0009 \\
\hline
\end{tabular}

sensitivity and specificity, which suggests an improved prediction. The variable importance plot indicated TMI as the most significant PV for large-area assessment of $L$. sinense, followed by VC TYPE, TRI, and vegetation density (Fig. 4b). The analysis of LiDAR PVs and the RF classifier with the county level field data mapped the spatial distribution of $L$. sinense that occupies $5.95 \%$ of forest understory, predominantly in drainage ways and lowland areas of forested landscapes along urban-rural gradients in the county (Fig. 7).

\section{Discussion}

Regional assessment of understory invasions requires an approach that overcomes the complicacies of spatial and vertical heterogeneity of forested landscapes, and utilizes structural and spectral remote sensing data in a coherent manner. In this study, we found that structural and spectral data from LiDAR can be used to detect $L$. sinense over large areas with greater accuracy than either using multispectral IKONOS data alone or the combination of predictors derived from LiDAR and IKONOS. We obtained high accuracy estimates using the RF classifier with selected LiDAR PVs at both the experimental and county extents (Table 4). Topographic attributes, including TMI and TRI, together with vegetation height and LiDAR's spectral metrics contributed the most in the detection of $L$. sinense, regardless of the classifier used.

Contrary to our expectations, high resolution IKONOS did not contribute significantly to the detection of $L$. sinense, revealing the limited ability of spectral remote sensing to unravel vertical structure of heterotypic forest stands. The ineffectiveness of IKONOS in the detection of $L$. sinense could be due to cumulative or individual constraints in spectral, spatial, and temporal resolutions. The heterogeneity of forest strata is responsible for the mixed spectral response resulting in scale-dependent variance. This could be further complicated with an off-nadir effect of tall trees on understory vegetation as found in (Hsieh et al., 2001) and (Myeong et al., 2006). Decreasing the spatial resolution of IKONOS spectral features to $5 \mathrm{~m}$ for spatial consistency across the analysis and the uneven georegistration between IKONOS and LiDAR may have also contributed to poor results (Nelson et al., 2006). A time lag in acquisition (a temporal gap) may also contribute to problematic integration of the two remote sensing data sources, which is also the case in this study. Accurate detection of understory plant invasions is scale (scale of the study) and data dependent, considering the types of data analyzed, the existing data dimensionality and nonlinearity, and the data acquisition period. The choice of classification techniques also influenced computational efficiency and detection success. Moreover, detection success is most dependent upon the characteristics of forested landscapes, including physiology of invasive shrubs and the host environment (Chastain and Townsend, 2007; Resasco et al., 2007).
Our approach of dividing PVs from LiDAR into variable types representing characteristics of forest structure and forested landscapes added a new element into the design of our analytical framework. The RF accuracy estimates of models based on LiDAR-derived variable type combinations (Table 3 ) illustrate the significance of forest structure and landscape characteristics and their contribution in detection and mapping $L$. sinense. The topography variables contributed the most with improved detection once combined with overall vegetation characteristics, and overstory using the RF classifier. Among our broad variable types, topographic moisture, roughness, vegetation height, and vegetation intensity profile were key variables in the RF and LR models at both extents (Fig. 4a and b, Table 4). Topographic moisture and roughness play important roles in the growth and distribution of $L$. sinense in riparian forests of the southeastern United States (Hudson et al., 2013; Wang and Grant, 2012), therefore, the influence of these variables in the analysis is not surprising. The significance of vegetation height, density, and intensity profiles variables supports our concept that physiological characteristics of $L$. sinense are the most suitable for LiDAR-based detection. The prominence of vegetation density and intensity variables in our analysis also suggests that LiDAR with higher point-density, acquired in the peak of senescence period, can improve detection and mapping by providing distinct spectral contrast and vegetation densities between deciduous and compact evergreen understory, which corroborates the findings of Straatsma and Middelkoop (2007).

Our $k$-fold CV of model performance helped minimize the over-fitting tendency of the RF classifier and provided a direct comparison between RF and LR models. The RF classifier outperformed the LR classifier using the same set of selected PVs. Cutler et al. (2007) observed higher performance using the RF classifier when there were strong interactions among the PVs. RF's ability to model complex interactions among PVs perhaps addresses the complicated interactions of LiDAR-derived PVs in the top performing model and explains the better performance of $\mathrm{RF}$ classifier. The common PVs in both classifiers, for example, TMI and $\mathrm{VI}_{\mathrm{SD}}$, and the marginal difference in AUC value suggests that the LR-derived probabilities might be useful for making rapid adjustments to thresholds that alter false positive/false negative rates to improve prediction of $L$. sinense. One disadvantage of LR is that it requires non-collinear variables, whereas RF is not affected by multicollinearity because the algorithm 'spreads' the variable importance across all the variables and keeps those which are good predictors of the response even when correlated with other PVs (Cutler et al., 2007). The unbalanced sample size is also one potential reason for the performance disparity between the two classifiers. The RF makes no distributional assumptions about the predictor or response variables and can automatically reanalyze the presence and absence class to achieve equal size, providing another 
advantage over LR. In general, a higher number of presence data in the model poses a challenge of overestimation. On the contrary, due to a higher number of absence data, more than twice the presence data at both extents, we expect that neither classifier overestimated the spatial distribution of $L$. sinense.

We identified two primary sources of error in the overestimation of 'sensitivities' in models: (1) the presence of other evergreen understory shrubs, and (2) the use of field plots containing a fewer number of seedlings, juveniles, and matures as presence in the classifiers. However, the effects of higher evergreen shrub coverage and plots with sparser $L$. sinense plants on detection and mapping are matters for further analysis. Other technical issues influencing accuracy estimates were GPS positional errors from the fieldwork, loss of information during data conversion (e.g., float to integer), and the quality of LiDAR data and derived variables at regional extents, including gaps between LiDAR tiles and non-calibrated LiDAR intensity. Computational challenges that arose due to large data volumes associated with the large-area LiDAR application suggest that we need to explore data reduction techniques and optimal resolutions for detection and mapping of understory plant invaders.

We observed little difference in accuracy estimates when implementing the RF classifier at the experimental and county extents, with only slightly reduced variability between resubstitution and $k$ fold CV at the county extent. This reduced variability is attributable to the larger amounts of field data at the county extent. However, similar accuracy estimates at both extents suggests the suitability of the RF classifier when less field data is available, which is consistent with research presented by Martinuzzi et al. (2009). County-level analyses showed that TMI and vegetation cover types - deciduous and evergreen - $\left(\mathrm{VC}_{\mathrm{TYPE}}\right)$ are the most important variables for predicting the distribution of $L$. sinense at that scale. Application of the RF classifier at the county extent prompted two methodological avenues for future research: (1) to analyze LiDARderived PVs with spatial resolution matching the field plot size (i.e., $10 \mathrm{~m} \times 10 \mathrm{~m}$ ) to enhance data handling and computational efficiency while providing sufficient accuracy estimates, and (2) to measure the variability in accuracy estimates when using other evergreen understory invasive species found in the field plots. Ultimately, using county-level field data with the RF classifier is suitable for large-area assessment of $L$. sinense, and this approach can be applied to other local and regional sites.

\section{Conclusions}

Successful management of native biodiversity and ecosystem services at regional scales requires methodological advances in the application of remote sensing technologies aiming to accurately quantify the spatial distribution of invasive species. Our results suggest that LiDAR data provides: (1) adequate information for accurately detecting and mapping the spatial distribution of the understory invasive $L$. sinense over large urbanizing regions, and (2) improved results as compared to the analysis of IKONOS optical imagery. The topography variables (TMI+TRI), when combined with overall vegetation characteristics (density + spectral) and overstory (height), produced the highest accuracy estimates. These findings highlight the significance of the structural and spectral characteristics of LiDAR for quantifying the landscapelevel topographic, forest stand, and physical and structural plant attributes used for detecting and mapping the distribution of $L$. sinense. LiDAR intensity-derived variables were significant in the successful detection and mapping of $L$. sinense, emphasizes the importance of the spectral attributes of LiDAR data for assessing understory invasives. This research demonstrates how categorizing LiDAR-derived variables into variable types representing overstory and understory forest structure and topography contributed to our understanding of the forest and landscape characteristics that influence the distribution, growth, and detection of $L$. sinense. Our study suggests an even distribution of $L$. sinense in forests along the urban-rural gradients of Mecklenburg County, NC, found predominantly in drainage ways, lowlands, and disturbed areas of forested landscapes as observed during fieldwork. This research further highlights the importance of LiDAR data acquisition during the leaf-off season for mapping $L$. sinense. Our methodological framework addresses data complexities, including multidimensionality and nonlinearity in multisource data, and provides a generalized approach for rapid assessments of $L$. sinense in forested landscapes over large urbanizing regions to support development and implementation of management plans for conserving native biodiversity.

\section{Acknowledgements}

This research was supported by the National Science Foundation ULTRA-Ex program (BCS-0949170), Renaissance Computing Institute (RENCI), Garden Club of America (GCA) Zone VI fellowship in urban forestry, Casey Trees Endowment Fund, and the AAG (Association of American Geographers) Dissertation Research grants. We express sincere thanks to Drs. Marguerite Madden, Hugh Devine, Stacy Nelson, and Helena Mitasova for their comments and feedback for shaping the research and manuscript. We thank S. Gagné (UNC Charlotte) for providing IKONOS data. We also thank fellow graduate students from the Center for Geospatial Analytics, North Carolina State University, for their comments and feedback on the manuscript.

\section{References}

Andrew, M.E., Ustin, S.L., 2009. Habitat suitability modelling of an invasive plant with advanced remote sensing data. Divers. Distrib. 15, 627-640.

Asner, G.P., Vitousek, P.M., 2005. Remote analysis of biological invasion and biogeochemical change. Proc. Natl. Acad. Sci. U. S. A. 102, 4383-4386.

Asner, G.P., Knapp, D.E., Kennedy-Bowdoin, T., Jones, M.O., Martin, R.E., Boardman, J., Hughes, R.F., 2008. Invasive species detection in Hawaiian rainforests using airborne imaging spectroscopy and LiDAR. Remote Sens. Environ. 112, 1942-1955.

BCAL LiDAR Tools (2013). Idaho State University, Department of Geosciences. In. Boise, Idaho: Boise Center Aerospace Laboratory (BCAL).

Becker, R., Zmijewski, K., Crail, T., 2013. Seeing the forest for the invasives: mapping buckthorn in the Oak openings. Biol. Invasions 15, 315-326.

Breiman, L., 2001. Random forests. Mach. Learn. 45, 5-32.

Brown, C.E., Pezeshki, S.R., 2000. A study on waterlogging as a potential tool to control Ligustrum sinense populations in western Tennessee. Wetlands 20, 429-437.

Carleer, A., Wolff, E., 2004. Exploitation of very high resolution satellite data for tree species identification. Photogramm. Eng. Remote Sens. 70, 135-140.

Chastain, R.A., Townsend, P.A., 2007. Use of landsat ETM and topographic data to characterize evergreen understory communities in appalachian deciduous forests. Photogramm. Eng. Remote Sens. 73, 563-575.

Cutler, D.R., Edwards, T.C., Beard, K.H., Cutler, A., Hess, K.T., 2007. Random forests for classification in ecology. Ecology 88, 2783-2792.

EDDMapS, 2014. Early Detection Distribution Mapping System. In. The University of Georgia - Center for Invasive Species and Ecosystem Health. The University of Georgia.

Estes, L.D., Reillo, P.R., Mwangi, A.G., Okin, G.S., Shugart, H.H., 2010. Remote sensing of structural complexity indices for habitat and species distribution modeling. Remote Sens. Environ. 114, 792-804.

Estornell, J., Ruiz, L.A., Velazquez-Marti, B., Fernandez-Sarria, A., 2011. Estimation of shrub biomass by airborne LiDAR data in small forest stands. For. Ecol. Manage. 262, 1697-1703.

Falkowski, M.J., Evans, J.S., Martinuzzi, S., Gessler, P.E., Hudak, A.T., 2009. Characterizing forest succession with lidar data: an evaluation for the Inland Northwest USA. Remote Sens. Environ. 113, 946-956.

Faulkner, J.L., Clebsch, E.E.C., Sanders, W.L., 1989. Use of Prescribed Burning for Managing Natural and Historic Resources in Chickamauga and Chattanooga National Military Park USA. Environ. Manage. 13, 603-612.

Franklin, S.E., Wulder, M.A., Gerylo, G.R., 2001. Texture analysis of IKONOS panchromatic data for Douglas-fir forest age class separability in British Columbia. Int. J. Remote Sens. 22, 2627-2632.

Glenn, N.F., Mundt, J.T., Weber, K.T., Prather, T.S., Lass, L.W., Pettingill, J., 2005. Hyperspectral data processing for repeat detection of small infestations of leafy spurge. Remote Sens. Environ. 95, 399-412. 
Goetz, S.J., Steinberg, D., Betts, M.G., Holmes, R.T., Doran, P.J., Dubayah, R., Hofton, M., 2010. Lidar remote sensing variables predict breeding habitat of a Neotropical migrant bird. Ecology 91, 1569-1576.

Greene, B.T., Blossey, B., 2012. Lost in the weeds: Ligustrum sinense reduces native plant growth and survival. Biol. Invasions 14, 139-150.

Guo, L., Chehata, N., Mallet, C., Boukir, S., 2011. Relevance of airborne lidar and multispectral image data for urban scene classification using random forests. ISPRS J. Photogramm. Remote Sens. 66, 56-66.

Hanula, J.L., Horn, S., Taylor, J.W., 2009. Chinese privet (Ligustrum sinense) remova and its effect on native plant communities of Riparian Forests. Invasive Plant Sci. Manage. 2, 292-300.

Hestir, E.L., Khanna, S., Andrew, M.E., Santos, M.J., Viers, J.H., Greenberg, J.A. Rajapakse, S.S., Ustin, S.L., 2008. Identification of invasive vegetation using hyperspectral remote sensing in the California Delta ecosystem. Remote Sens. Environ. 112, 4034-4047.

Homolova, L., Maenovsky, Z., Clevers, J.G.P.W., Garcia-Santos, G., Schaeprnan, M.E. 2013. Review of optical-based remote sensing for plant trait mapping. Ecol. Complex. 15, 1-16.

Hsieh, P.F., Lee, L.C., Chen, N.Y., 2001. Effect of spatial resolution on classification errors of pure and mixed pixels in remote sensing. IEEE Trans. Geosci. Remote Sens. 39, 2657-2663.

Huang, C.-Y., Asner, G.P., 2009. Applications of remote sensing to alien invasive plant studies. Sensors 9, 4869-4889.

Hudak, A.T., Crookston, N.L., Evans, J.S., Hall, D.E., Falkowski, M.J., 2008. Nearest neighbor imputation of species-level, plot-scale forest structure attributes from LiDAR data. Remote Sens. Environ. 112, 2232-2245.

Hudson, J.R., Hanula, J.L., Horn, S., 2013. Removing Chinese privet from riparian forests still benefits pollinators five years later. Biol. Conserv. 167, 355-362.

Iverson, L.R., Dale, M.E., Scott, C.T., Prasad, A., 1997. A GIS-derived integrated moisture index to predict forest composition and productivity of Ohio forests (USA). Landscape Ecol. 12, 331-348.

Jaskierniak, D., Lane, P.N.J., Robinson, A., Lucieer, A., 2011. Extracting LiDAR indices to characterise multilayered forest structure using mixture distribution functions. Remote Sens. Environ. 115, 573-585.

Kayitakire, F., Hamel, C., Defourny, P., 2006. Retrieving forest structure variables based on image texture analysis and IKONOS-2 imagery. Remote Sens. Environ. 102, 390-401.

Keating, K.A., Gogan, P.J.P., Vore, J.M., Irby, L.R., 2007. A simple solar radiation index for wildlife habitat studies. J. Wildl. Manage. 71, 1344-1348.

Laba, M., Downs, R., Smith, S., Welsh, S., Neider, C., White, S., Richmond, M., Philpot, W., Baveye, P., 2008. Mapping invasive wetland plants in the Hudson River National Estuarine Research Reserve using quickbird satellite imagery. Remote Sens. Environ. 112, 286-300.

Langeland, K.A., Burks, K.C., 1998. In: Langeland, K.A., Burks, K.C. (Eds.), Identification and Biology of Non-Native Plants in Florida's Natural Areas. University of Florida, Gainesville, p. 165.

Lawrence, R.L., Wood, S.D., Sheley, R.L., 2006. Mapping invasive plants using hyperspectral imagery and Breiman-Cutler classifications (Random forest). Remote Sens. Environ. 100, 356-362.

Linderman, M., Liu, J., Qi, J., An, L., Ouyang, Z., Yang, J., Tan, Y., 2004. Using artificial neural networks to map the spatial distribution of understorey bamboo from remote sensing data. Int. J. Remote Sens. 25, 1685-1700.

Martinuzzi, S., Vierling, L.A., Gould, W.A., Falkowski, M.J., Evans, J.S., Hudak, A.T., Vierling, K.T., 2009. Mapping snags and understory shrubs for a LiDAR-based assessment of wildlife habitat suitability. Remote Sens. Environ. 113, 2533-2546.

Merriam, R.W., Feil, E., 2002. The potential impact of an introduced shrub on native plant diversity and forest regeneration. Biol. Invasions 4, 369-373.

Miller, J.H., Chambliss, E.B., Oswalt, C.M., 2008. Maps of occupation and estimates of acres covered by nonnative invasive plants in southern forests using SRS FIA data. In.

Mutlu, M., Popescu, S.C., Stripling, C., Spencer, T., 2008. Mapping surface fue models using lidar and multispectral data fusion for fire behavior. Remote Sens. Environ. 112, 274-285.

Myeong, S., Nowak, D.J., Duggin, M.J., 2006. A temporal analysis of urban forest carbon storage using remote sensing. Remote Sens. Environ. 101, 277-282.

Nelson, S.A.C., Cheruvelil, K.S., Soranno, P.A., 2006. Satellite remote sensing of freshwater macrophytes and the influence of water clarity. Aquat. Bot. 85 , 289-298.
Orka, H.O., Wulder, M.A., Gobakken, T., Naesset, E., 2012. Subalpine zone delineation using LiDAR and Landsat imagery. Remote Sens. Environ. 119 11-20.

Popescu, S.C., Wynne, R.H., Scrivani, J.A., 2004. Fusion of small-footprint lidar and multispectral data to estimate plot-level volume and biomass in deciduous and pine forests in Virginia USA. For. Sci. 50, 551-565.

Prasad, A.M., Iverson, L.R., Liaw, A., 2006. Newer classification and regression tree techniques: bagging and random forests for ecological prediction. Ecosystems 9, 181-199.

Pu, R.L., 2011. Mapping urban forest tree species using IKONOS imagery: preliminary results. Environ. Monit. Assess. 172, 199-214.

R Core Team (2013). R: A Language and Environment for Statistical Computing. In. Vienna, Austria: R Foundation for Statistical Computing.

Resasco, J., Hale, A.N., Henry, M.C., Gorchov, D.L., 2007. Detecting an invasive shrub in a deciduous forest understory using late-fall Landsat sensor imagery. Int. J. Remote Sens. 28, 3739-3745.

Royo, A.A., Carson, W.P., 2006. On the formation of dense understory layers in forests worldwide: consequences and implications for forest dynamics, biodiversity and succession. Can. J. For. Res. 36, 1345-1362.

Rushton, S.P., Ormerod, S.J., Kerby, G., 2004. New paradigms for modelling species distributions? J. Appl. Ecol. 41, 193-200.

Simberloff, D., Martin, J.L., Genovesi, P., Maris, V., Wardle, D.A., Aronson, J., Courchamp, F., Galil, B., Garcia-Berthou, E., Pascal, M., Pysek, P., Sousa, R., Tabacchi, E., Vila, M., 2013. Impacts of biological invasions: what's what and the way forward. Trends Ecol. Evol. 28, 58-66.

Singh, K.K., Vogler, J.B., Meng, Q., Meentemeyer, R.K., 2010. Mapping land use patterns in an urbanizing landscape using LiDAR intensity data. In: In, Optica Remote Sensing of the Environment. Optical Society of America, Tucson, AZ, pp. OMC2.

Singh, K.K., Vogler, J.B., Shoemaker, D.A., Meentemeyer, R.K., 2012. LiDAR-Landsa data fusion for large-area assessment of urban land cover: balancing spatial resolution data volume and mapping accuracy. ISPRS J. Photogramm. Remote Sens. 74, 110-121.

Singh, K.K., Chen, G., McCarter, J.B., Meentemeyer, R.K., 2015. Effect of LiDAR point density and landscape context on estimates of urban forest biomass. ISPRS J. Photogramm. Remote Sens., In Press http://dx.doi.org/10.1016/j.isprsjprs.2014.12.021

Stambaugh, M.C., Guyette, R.P., 2008. Predicting spatio-temporal variability in fire return intervals using a topographic roughness index. For. Ecol. Manage. 254, 463-473.

Straatsma, M., Middelkoop, H., 2007. Extracting structural characteristics of herbaceous floodplain vegetation under leaf-off conditions using airborne laser scanner data. Int. J. Remote Sens. 28, 2447-2467.

Stumpf, A., Kerle, N., 2011. Object-oriented mapping of landslides using random forests. Remote Sens. Environ. 115, 2564-2577.

Tuanmu, M.N., Vina, A., Bearer, S., Xu, W.H., Ouyang, Z.Y., Zhang, H.M., Liu, J.G. 2010. Mapping understory vegetation using phenological characteristics derived from remotely sensed data. Remote Sens. Environ. 114, 1833-1844

USFWS, 1991. Endangered and threatened wildlife and plants: determination of Helianthus schweinitzii (Schweinitz's sunflower) to be an endangered species. Fed. Regist. 56, 21087-21091.

Ulyshen, M.D., Horn, S., Hanula, J.L., 2010. Response of beetles (Coleoptera) at three heights to the experimental removal of an invasive shrub, Chinese privet (Ligustrum sinense) from floodplain forests. Biol. Invasions 12, 1573-1579.

Wang, H.H., Grant, W.E., 2012. Determinants of Chinese and European privet (Ligustrum sinense and Ligustrum vulgare) invasion and likelihood of further invasion in southern U.S. forestlands. Invasive Plant Sci. Manage. 5 454-463.

Wang T.J., Skidmore, A.K., Toxopeus, A.G., 2009. Improved understorey bamboo cover mapping using a novel hybrid neural network and expert system. Int. J. Remote Sens. 30, 965-981.

Waske, B., van der Linden, S., Oldenburg, C., Jakimow, B., Rabe, A., Hostert, P., 2012. imageRF - a user-oriented implementation for remote sensing image analysis with random forests. Environ. Model. Software 35, 192-193.

Wilfong, B.N., Gorchov, D.L., Henry, M.C., 2009. Detecting an invasive shrub in deciduous forest understories using remote sensing. Weed Sci. 57, 512-520.

Wing, B.M., Ritchie, M.W., Boston, K., Cohen, W.B., Gitelman, A., Olsen, M.J., 2012. Prediction of understory vegetation cover with airborne lidar in an interior ponderosa pine forest. Remote Sens. Environ. 124, 730-741. 